\title{
CREEP BEHAVIOUR OF CONCRETE WITH GLASS WASTE MICROFILLER
}

\author{
Andina Sprince ${ }^{1}$, Aleksandrs Korjakins ${ }^{2}$, Leonids Pakrastinsh ${ }^{1}$ \\ 1- Riga Technical University, Department of Structural Engineering \\ 16 Azenes Str., Riga, LV 1048, Latvia \\ Ph.: (+371)67089145, fax: +(371)67089195; e-mail: andina.sprince@ rtu.lv; \\ leonids.pakrastins@rtu.lv \\ 2- Riga Technical University, Institute of Materials and Structures \\ 16 Azenes Str., Riga, LV 1048, Latvia \\ Ph.: (+371)7089248; fax: (+371)7089248, e-mail: aleksandrs.korjakins@ rtu.lv
}

\begin{abstract}
Every year there are several hundred tons of waste glass produced in Latvia. Glass can be re-used as a fine raw material and it presents a possibility to save natural, non-renewable materials. The use of glass powder in concrete production can make the construction industry more environmentally friendly. This paper examines the possibility of using glass powder as cement replacement in a new type of concrete. In the experiment, cement was partially (20\% and 40\%) replaced with glass powder. The long-term deformation (creep) of this new concrete was monitored. Three different concrete mixtures were batched. Specimens of $20 \%$ and $40 \%$ cement replacement were compared with the specimens made of standard concrete. The samples were tested in two extreme conditions: in one case they were kept in 100\% humidity ensured by preventing the desiccation of the concrete, and in the other case samples were air-dried by preventing them from becoming wet. Compression strength and modulus of elasticity of 7 and 28 days old cubic samples was determined.
\end{abstract}

Keywords: compression strength, creep, glass powder, long-term deformations, modulus of elasticity.

\section{Introduction}

In the last few years it has been recognized that one of the main sources of environmental pollution is waste. It has become a major environmental problem because many types of waste do not break down, that is, essential physical, biological and chemical changes do not take place. One of the possibilities of utilizing waste is recycling, which would not only save natural resources, but also decrease the amount of deposited waste. Glass waste requires recycling. Since there are different types of glass with different chemical compositions, there are also different possibilities of its use. In accordance with the decision of the European Committee, all simple incandescent lamps are to be replaced by fluorescent lamps until 2012, therefore after a couple of years the problem of their recycling and utilization will become more severe [1]. One of the solutions would be to recycle the lamp glass by using it in concrete production, where it can partly replace fine sand or cement and thus help create a new construction material. Using lamp glass powder (LGP) in concrete is an interesting possibility for economy on waste disposal sites and conservation of natural resources [2].

One of the main constituents of standard concrete is cement. Every year approximately 2.35 billion tons of cement are produced - that is almost $1 \mathrm{~m}^{3}$ of cement for every person in the world. The carbon dioxide released into the atmosphere during the cement production process accounts for approximately $5-10 \%$ of the overall $\mathrm{CO}_{2}$ production in the world. Its release into the atmosphere contributes to the global warming and the development of holes in the ozone layer. If the $\mathrm{CO}_{2}$ production in cement factories could be decreased by $10 \%$, the overall release into the atmosphere would decrease by $5.2 \%$. Using waste glass as cement replacement in concrete construction sector is advantageous, as the production cost of concrete would decrease, and our industry would become more environmentally friendly [2]. The deformation characteristics of a material are just as important as its strength properties. Concrete is an important structural material used in every country of the world, in the oceans, 
under ground, and in virtually every type of construction. Moreover, the complexity of structures and their size have continued to increase, and this has resulted in a greater importance of their deformation characteristics and in more serious consequences of their behavior [3]. One type of strain that plays a major role in successful and continuous use of structures is creep - deformations that appear due to long-term loading of the structural element. Under constant mechanical loading, the strain of concrete increases significantly with loading duration, the increase often reaching 2 to 3 times the value of the instantaneous strain [4]. Therefore, designers and engineers need to know the creep properties of concrete and must be able to take them into account in the structure analysis. After all, the end product of an engineer's endeavours is a structure whose strength is adequate, but not wastefully excessive, whose durability is commensurate with the conditions of exposure, and whose serviceability ensures fitness for the purpose. Consideration of creep is a part of a rational approach to satisfying these criteria. Deformation characteristics of materials are an essential feature of their properties, and a vital element in the knowledge of their behaviour. After all, it is the subject that matters: creep is important if its deformation increases with time under a constant stress [3].

The objective of this paper is to present the results of experimental investigations of the longterm deformation (creep) of concrete samples containing glass powder. Cement was substituted by weight with glass powder at rates varying from 20 to 40 per cent. The compressive strength and modulus of elasticity of concrete materials made with glass powder were studied and compared with those of standard specimens.

\section{Materials and methods}

One of the goals of the experiment was to find out whether the new concrete composition can be competitive and whether its physical and mechanical properties are equivalent to those of standard concrete. The object of this study was lamp glass powder (LGP) obtained from fluorescent lamp waste. The other raw materials used for this study were natural coarse aggregate, fine aggregate and normal cement CEM I $42.5 \mathrm{~N}$ (Kunda).

The experiment consisted of replacing cement with glass powder in amounts of 0,20 and 40 per cent. Standard sample cubes 150x150x150 mm were produced in order to investigate the mechanical characteristics of the material (see Fig. 1). Concrete mixtures were cast into oiled steel moulds and

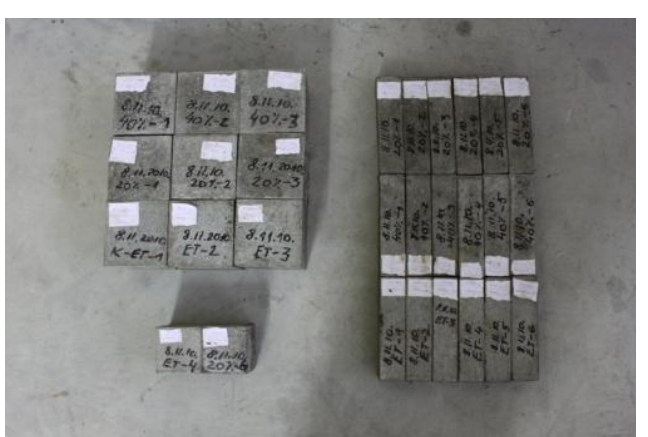

Fig. 1. Specimens containing lamp glass powder compacted at the vibrating table. After two days the moulds were removed. Standard

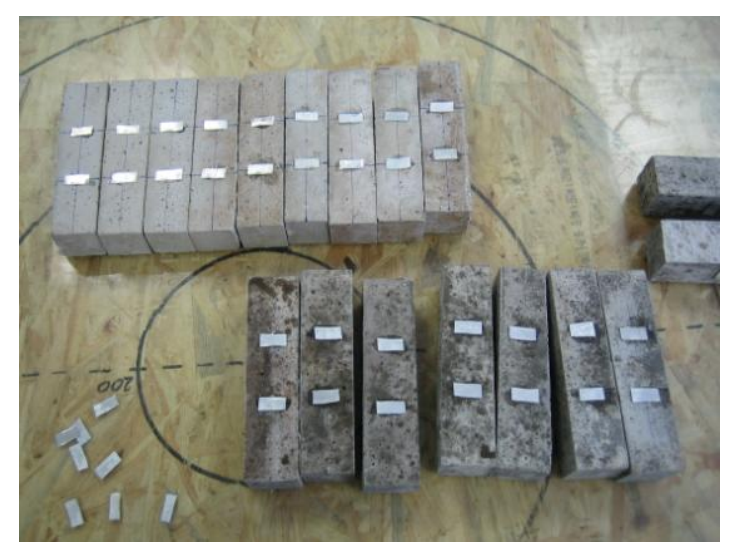

Fig. 2. Specimens with steel plates hardening conditions (temperature $+20^{\circ} \mathrm{C}$, $\mathrm{RH}>95 \%$ ) were provided. After the hardening period, the samples were measured and tested in standard conditions. Their compression strength was determined in conformity with LVS EN 12390-3:2002. A testing machine with accuracy $+1 \%$ was used, and the rate of loading was $0.7 \mathrm{MPa} / \mathrm{sec}$. The samples were tested at the age of 7 and 28 days. Compression strength and density of the hardened concrete were determined. 


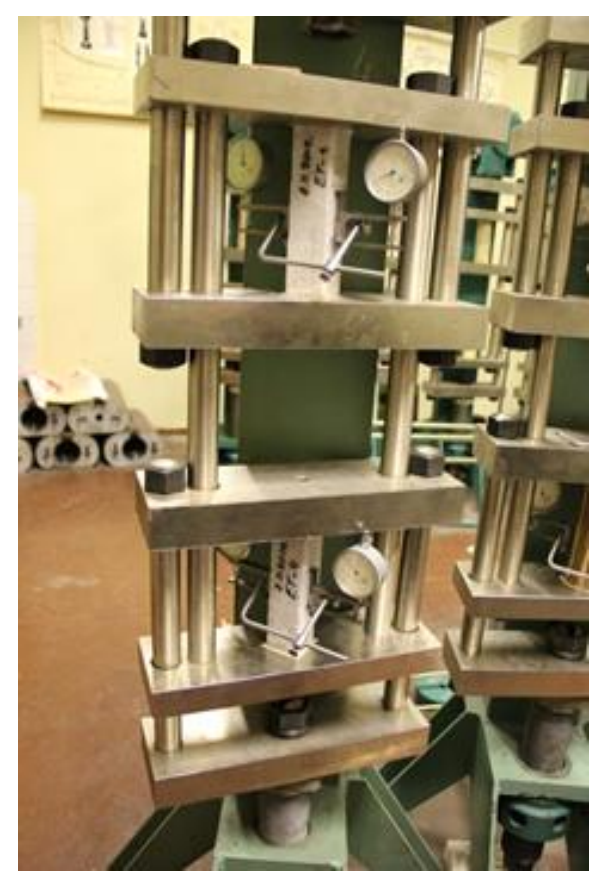

Fig. 3. Creep lever test stand

Creep experiments were carried out on prismatic 40x40x $160 \mathrm{~mm}$ samples that had been weighted both before and after the test (see Fig. 1). The creep (time-dependent strain) was measured in hardened concrete specimens subjected to a uniform compressive load kept constant over a long period of time. Load was applied gradually in 4 steps and as quickly as possible. At the beginning of the test, the samples were 50 days old, and they were kept under constant load for 60 days. The constant compressive load was equal to $40 \%$ of the maximum strength of the concrete, which had been determined in destructive tests carried out on the cubic samples [4]. The tests were conducted in two extreme conditions. In one case no moisture exchange with the environment was permitted, which was ensured by protecting the specimens against desiccation, and in the other case drying was permitted under conventional conditions, by protecting the specimens against moisture [4]. In order to prevent humidity exchange between the specimen and the environment, the surface of the specimens was coated with two protective silicone layers. Before this sealing, four steel plates were centrally and symmetrically glued onto two sides of the test prism in order to provide a basis for the strain gauges. The distance between two plates was $50 \mathrm{~mm}$. Two $+/-0.01 \mathrm{~mm}$ precision strain gauges were symmetrically connected to each sample, and then the samples were put into a creep lever test stand and loaded (see Fig. 3). They were kept in a dry atmosphere of controlled relative humidity in standard conditions: temperature $23 \pm 1^{\circ} \mathrm{C}$ and relative humidity $25 \pm 3 \%$.

\section{Results and discussion}

The tests to determine creep, modulus of elasticity, density and compression strength were done on concrete cubes in which LGP was used to replace $0 \%, 20 \%$ and $40 \%$ of the cement weight. Experimental work made it possible to compare the strength of standard concrete samples and samples containing LGP. Strength tests were carried out after 7 and 28 days of hardening in standard conditions (see Fig. 4).

Concrete samples containing LGP as a microfiller displayed a reduction in compression strength when compared to the standard concrete samples. The concrete containing LGP showed lower strength in the first 7 days, but on the $28^{\text {th }}$ day the strength increased and was very similar to that of standard concrete.

Fine glass powder caused a long-term hardening effect (see Fig. 5). Specimens with 40\% cement replacement showed a $70.6 \%$ increase of compression strength, while the specimens with $20 \%$ cement replacement showed a $43.4 \%$ increase of compression strength. Standard specimens, however, showed only a $15.3 \%$ increase of compression strength.

Fig. 6 shows the density of concrete cubes. The average density of standard concrete specimens hardened in moist conditions was $2.278 \mathrm{~kg} / \mathrm{m}^{3}$, and the average density of dryhardened specimens was $2.374 \mathrm{~kg} / \mathrm{m}^{3}$. The average density of concrete samples containing a $20 \%$ replacement of LGP was $2.267 \mathrm{~kg} / \mathrm{m}^{3}$ and $2.259 \mathrm{~kg} / \mathrm{m}^{3}$ respectively, and the average density of specimens containing a $40 \%$ replacement of LGP $-2.134 \mathrm{~kg} / \mathrm{m}^{3}$ and $2.251 \mathrm{~kg} / \mathrm{m}^{3}$. The average density of standard specimens hardened in moist conditions was larger by approximately $4.3 \%$, and for specimens containing $40 \%$ cement replacement it was larger by approximately $5.5 \%$. The average density of moist-hardened specimens containing 20\% 
cement replacement was, however, lower by approximately $0.35 \%$. The difference between the densities of standard and $40 \%$ cement replacement concrete samples hardened in dry and moist conditions was approximately $6 \%$. Between standard and $20 \%$ cement replacement concrete samples it was approximately $0.5 \%$ in dry conditions and approximately $4.8 \%$ in moist conditions. The density difference between $20 \%$ and $40 \%$ cement replacement concrete samples hardened in dry conditions was approximately $6 \%$ and between samples hardened in moist conditions it was approximately $0.35 \%$.

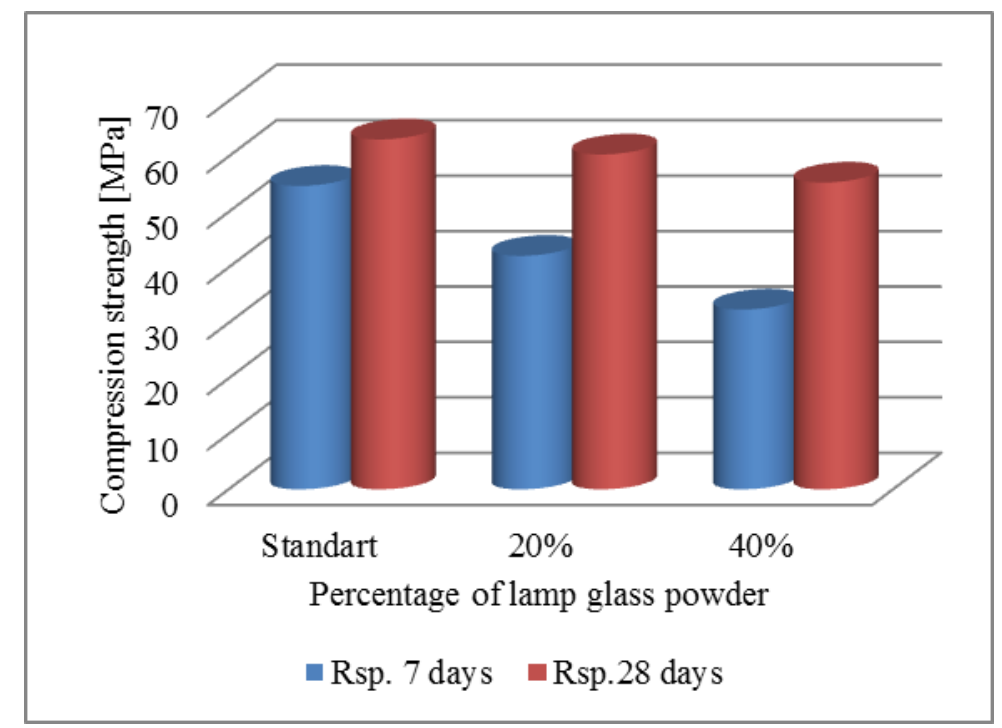

Fig. 4. Compressive strength at 7 and 28 days [MPa]

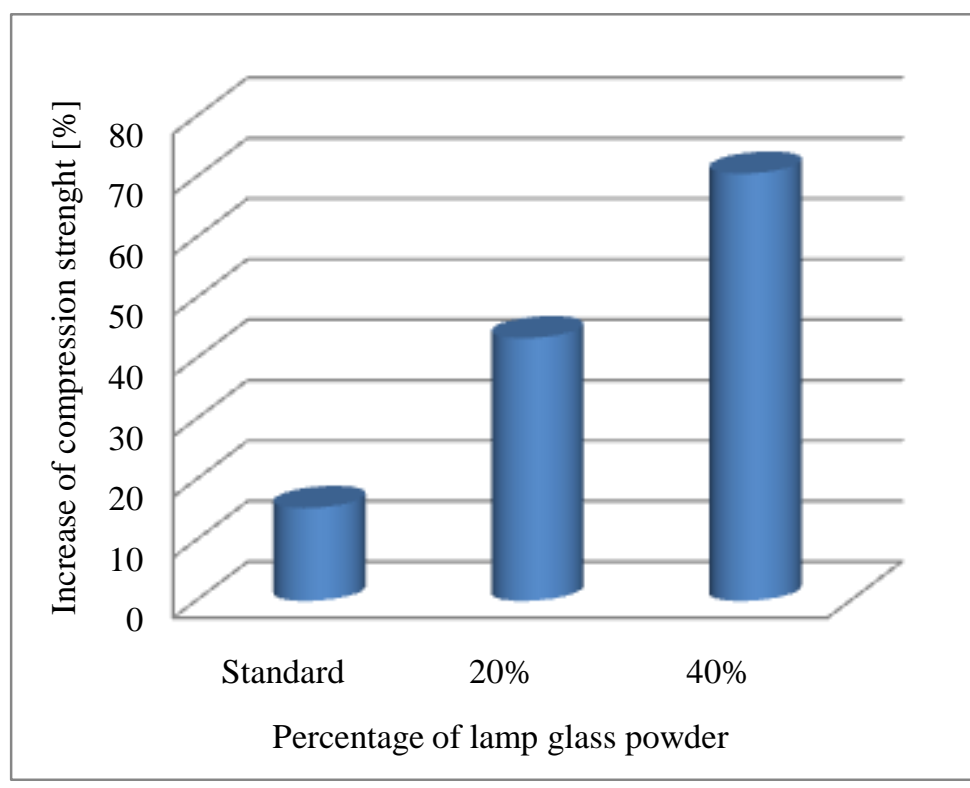

Fig. 5. Increase of compression strength (from 7 days to 28 days) $\%$ 


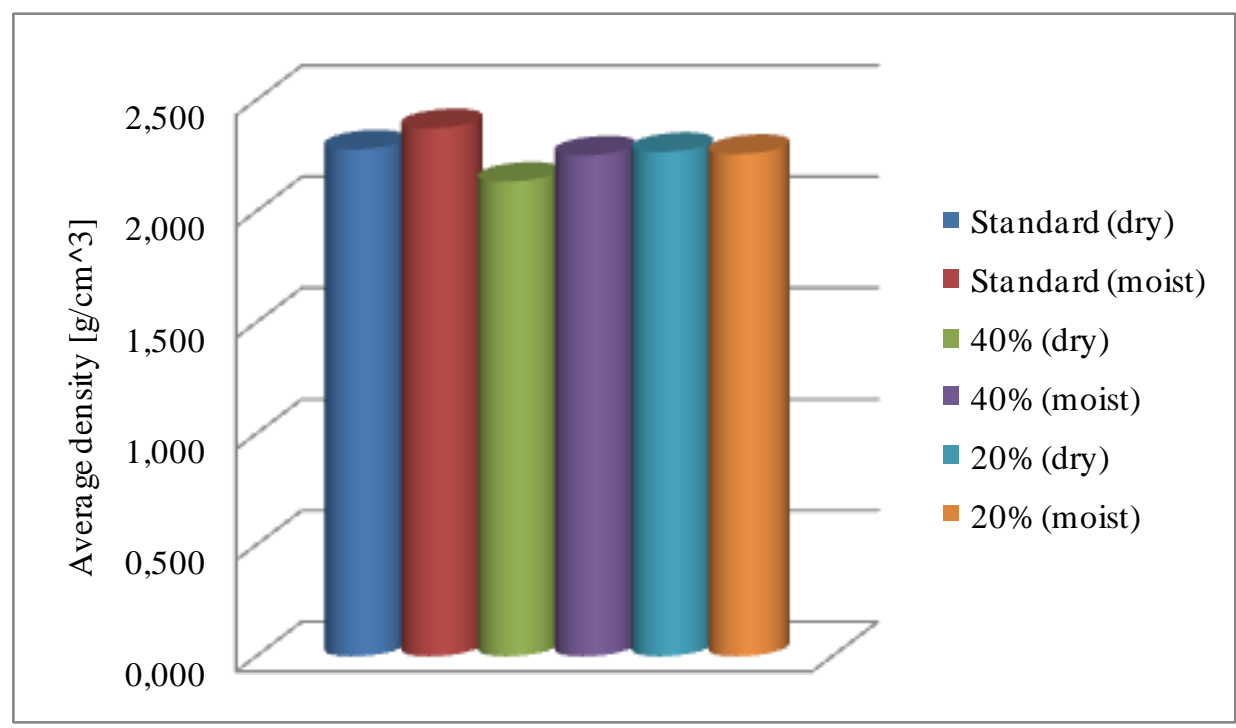

Fig. 6. Average densities of different concrete

The modulus of elasticity (see Fig. 7) was determined by measuring the deformations on the sides of the samples according to Hooke's law. For standard concrete the difference between samples hardened in moist and dry conditions is approximately $2.8 \%$. For samples containing $20 \%$ cement replacement, this difference is approximately $\mathrm{t}$ is $12.4 \%$ and for samples with $40 \%$ cement replacement it is $27.4 \%$. The comparison of the modulus of elasticity of standard concrete samples and samples containing a $40 \%$ cement replacement shows that for samples hardened in moist conditions this difference is $11.7 \%$, while for samples hardened in dry conditions it is $32.6 \%$. The corresponding differences between standard concrete samples and samples containing a $20 \%$ cement replacement is $2.9 \%$ and $16.3 \%$ respectively. The same tendency can also be seen from the stress-strain relation, which is a function of time (see Fig. 8).

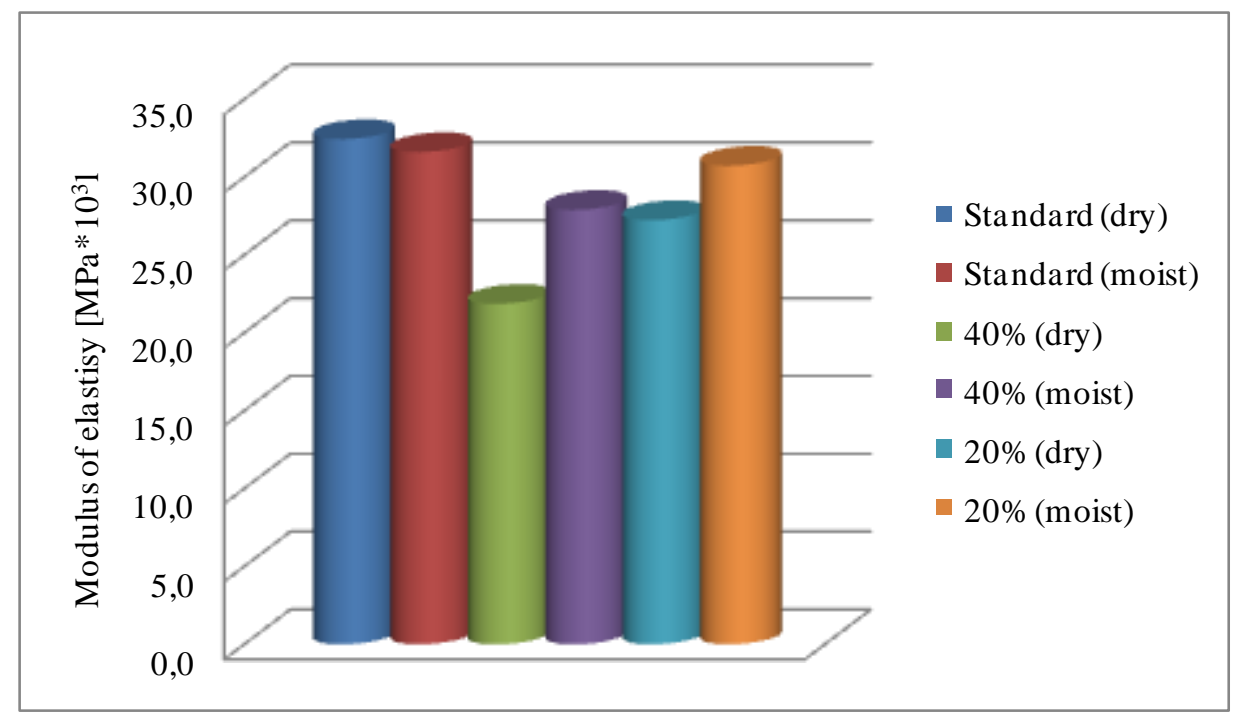

Fig. 7. Modulus of elastisy of different concrete 


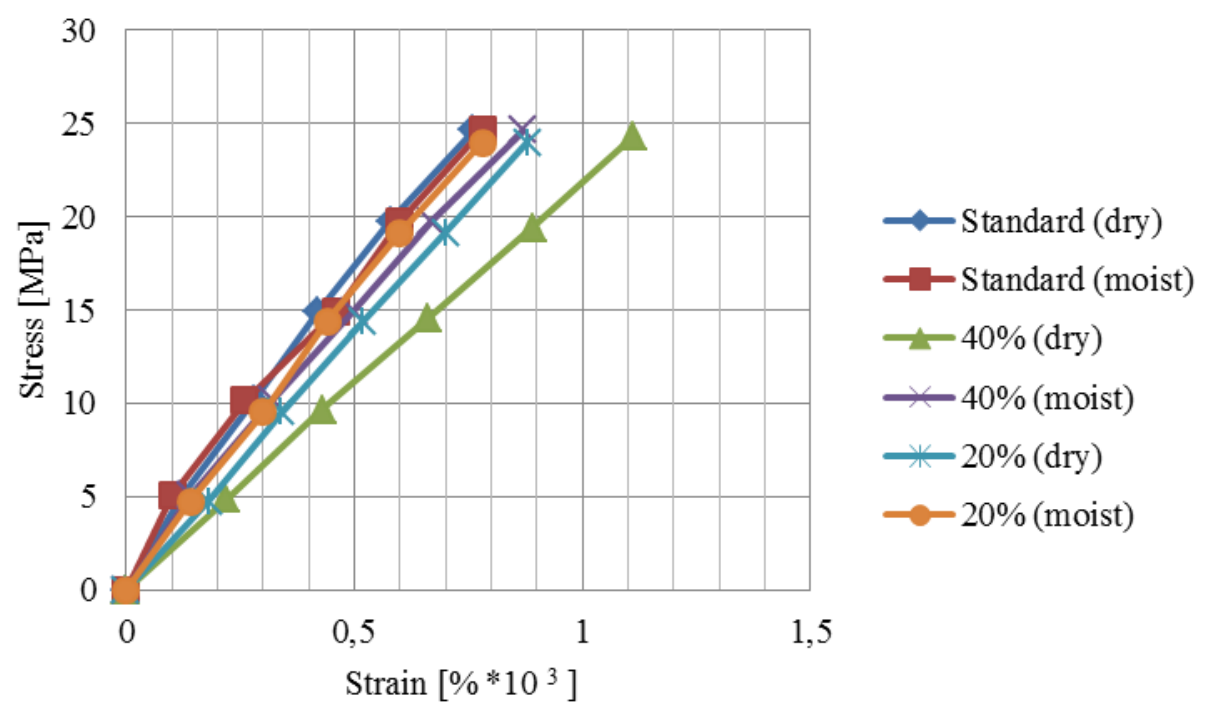

Fig. 8. Relation between stress and strain

The graph in Figure 9 shows linear creep - the stresses are almost proportional to the strain, and therefore the stresses do not reach the point of microcracking. From the gathered data it is evident that creep developed in standard concrete samples hardened in moist and dry conditions, whereas the smallest creep is exhibited by concrete samples containing a $20 \%$ cement replacement. The average difference between standard concrete samples hardened in moist and in dry conditions is approximately $4.2 \%$. For samples containing a $40 \%$ cement replacement this difference is approximately $11.9 \%$, and for samples containing a $20 \%$ cement replacement it is $13.5 \%$. If we compare the average difference between the standard concrete samples and the ones containing a $40 \%$ cement replacement, we can see that for samples hardened in moist conditions this difference is $38.7 \%$, and for samples hardened in dry conditions it is $38 \%$. In comparison with the $20 \%$ cement replacement concrete samples, the difference is $46 \%$ and $41.4 \%$ respectively.

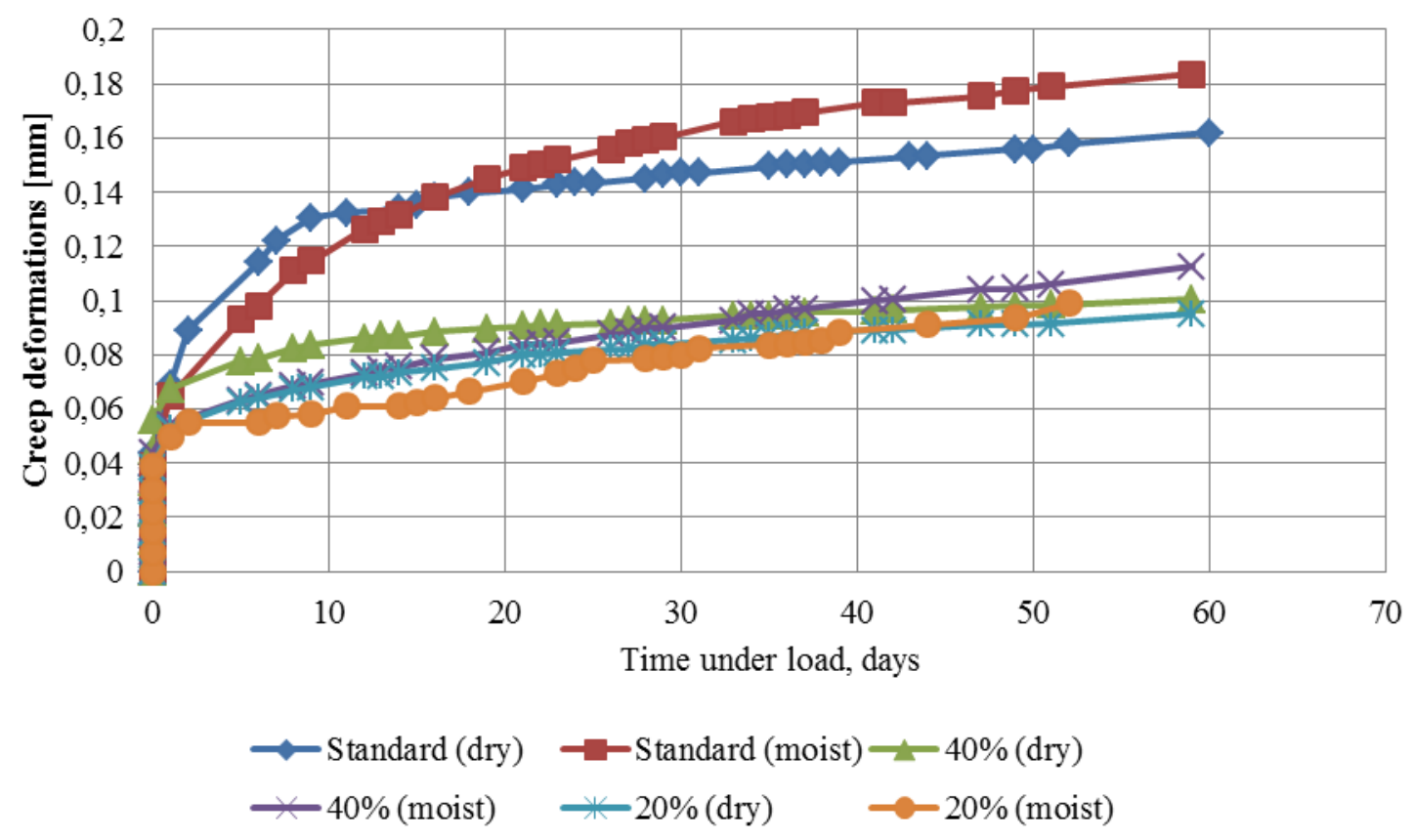

Fig. 9 Creep of concrete 
The results of the experiments are presented in Table 1 .

Physical and mechanical properties of concrete compositions

\begin{tabular}{|c|c|c|c|c|c|}
\hline Specimen & $\begin{array}{l}\text { Age, } \\
\text { days }\end{array}$ & $\begin{array}{c}\text { Density, } \\
\text { kg/m } \\
\text { (dry) }\end{array}$ & $\begin{array}{l}\text { Compression } \\
\text { strength, MPa }\end{array}$ & $\begin{array}{c}\text { Modulus of } \\
\text { elasticity, } \\
\text { GPa }\end{array}$ & $\begin{array}{c}\text { Creep } \\
\text { coefficient } \\
\text { (60 days) } \\
\end{array}$ \\
\hline Standard & 7 & 2297 & 55 & 32,5 (dry) & 3,7 (dry) \\
\hline Standard & 28 & 2293 & 63 & 31,6 (moist) & 4,7 (moist) \\
\hline $20 \%$ & 7 & 2246 & 42 & 21,9 (dry) & 2,5 (dry) \\
\hline $20 \%$ & 28 & 2253 & 60 & 27,9 (moist) & 2,54 (moist) \\
\hline $40 \%$ & 7 & 2196 & 32 & 27,2 (dry) & 1,8 (dry) \\
\hline $40 \%$ & 28 & 2199 & 55 & 30,7 (moist) & 2,1 (moist) \\
\hline
\end{tabular}

\section{Conclusions}

From the previously described tests, in which LGP was used as concrete microfiller instead of cement, the following main conclusions can be drawn: the lamp glass powder is available in significant quantities as waste and can be used for making concrete.

Long-term deformation testing was carried out, and the modulus of elasticity, the density and the compression strength of ordinary concrete and ones containing lamp glass powder were determined. Creep test results were summarized on the 60th day.

In the future the physical and mechanical properties of this new LGP concrete should be investigated in a more detailed way. Experimental results can be used to predict creep deformations. In order to decrease the dispersion of results, the number of specimens and tests should be increased.

This study proves that lamp glass can be successfully recycled and used in the production of concrete, thus potentially decreasing the amount of deposited waste and the use of cement, which would lead to a reduction of carbon dioxide release into the atmosphere.

\section{Acknowledgement}

This work has been supported by the European Social Fund within the scope of the project "Support for the Implementation of Doctoral Studies at Riga Technical University".

\section{References}

1. Korjakins A., Shakhmenko G., Bumanis G. The Use of Borosilicate Glass Waste as Concrete Micro-Filler. Proceeding of $2^{\text {nd }}$ International Conference of Advanced Construction, 2010, Kaunas, Lithuania, pp. 129134.

2. Mageswaril M. and Vidivelli B. The Use of Sheet Glass Powder as Fine Aggregate Replacement in Concrete. The Open Civil Engineering Journal, 2010, 4, pp. 65-71

3. Neville A. M., Dilger W. H., Brooks J. J. Neville. Creep of Plain and Structural Concrete. Construction press, 1983, London and New York, pp. 3, 11

4. Rilem TC 107-CSP: creep and shrinkage prediction models: principles of their formation. Measurement of time-dependent strains of concrete. Materials and Structure, Vol. 31, October 1998, pp. 507-512 